\title{
Estudo do efeito da inundação na variação de volume, na resistência de ponta e no módulo de elasticidade de um solo colapsível do Semiárido de Pernambuco
}

\author{
Study of the flood effect on volume change, \\ point resistance and modulus of elasticity of \\ a collapsible soil in Pernambuco's semi-arid
}

Jesce John da Silva Borges ${ }^{1}$, Moacy Silva Torres ${ }^{1}$,Klayde Janny da Silva Veríssimo ${ }^{1}$
Marta Lúcia de Almeida Almendra Freitas ${ }^{2}$, Silvio Romero de Melo Ferreira ${ }^{1}$

\author{
${ }^{1}$ Universidade Federal de Pernambuco - UFPE, CEP 50740-530, Recife, PE \\ e-mail: jescejohn@hotmail.com, moacyatc@hotmail.com, klaydejanny@hotmail.com,sr.mf@hotmail.com \\ ${ }^{2}$ Universidade Católica de Pernambuco - UNICAP, CEP 50050-900, Recife, PE \\ e-mail: marta.rolim@uol.com.br
}

\begin{abstract}
RESUMO
Solos colapsíveis apresentam comportamento hidromecânico diferenciado quando inundados. O artigo analisa a variação de volume, da resistência de ponta e do módulo de elasticidade de um solo colapsível de Petrolina-PE devido à inundação. O programa de investigação geotécnica desenvolvido em campo abrangeu: sondagens de simples reconhecimento; coleta de amostras indeformadas e deformadas; ensaios com penetrômetros estático e dinâmico DPL (Dynamic Petermeter Light); ensaios com o Light Weight Deflectometer - LWD e ensaios de colapsibilidade com o Expansocolapsômetro no solo natural e inundado. Em laboratório, foram realizados ensaios para a caracterização física, química, microestrutural e ensaios edométricos simples e duplos para avaliar a colapsibilidade do solo devido à inundação. Através dos estudos verificou-se que o solo é arenoso, verdadeiramente colapsível, tem uma estrutura com poros do tipo de empacotamento simples e apresenta colapso máximo na tensão de $160 \mathrm{kPa}$, obtido através do ensaio edométrico duplo. O colapso obtido em campo foi menor do que o obtido em laboratório e o tempo para ocorrer o colapso foi maior em campo. O módulo de elasticidade varia de 46,3 a 79,2 $\mathrm{MPa}$ e a inundação causa uma redução de $88 \%$ desses valores. A partir dos módulos de elasticidade obtidos com LWD estabeleceu-se um critério de suscetibilidade para solos colapsíveis por meio do coeficiente $\mathrm{K}_{\mathrm{LWD}}$, sendo: alto para $\mathrm{K}_{\mathrm{LWD}}>4,20$, baixo para $\mathrm{K}_{\mathrm{LWD}}<2,80$ e médio para $\mathrm{K}_{\mathrm{LWD}}$ entre 2,80 e 4,20. Há boas correlações entre as deflexões obtidas com o LWD e os deslocamentos por golpes obtidos com o DPL, observando-se que quando a deflexão é baixa, o índice de penetração é baixo, demonstrando maior rigidez do solo.
\end{abstract}

Palavras-chave: solo colapsível, LWD, DPL. Critério de suscetibilidade

\begin{abstract}
Collapsible soils have a different hydromechanical when inundated. The paper analyzes the variation of volume, the point resistance and modulus of elasticity of a collapsible soil Petrolina due to wetting. The geotechnical investigation program developed field covers: reconnaissance boring wih SPT; collect undisturbed samples and deformed; tests with penetrometers static e dynamic DPL (Dynamic Light Petermeter); trials with Light Weight Deflectometer - LWD and test collapsibility with Expansocolapsômetro in natural and flooded soil. In laboratory tests were performed to the physical, chemical, microstructural characteristics and standard and double edometric testes to evaluate the soil collapsibility due to wetting. The soil is truly collapsible, has a structure with pores of simple packaging type and has a maximum collapse in the $160 \mathrm{kPa}$ pressure. The collapse field smaller than that obtained in the laboratory and the time for the collapse process occurs is greater in the field. The results show that the elasticity modulus varies from 46.3 to $79.2 \mathrm{MPa}$ and flooding causes a $88 \%$ these values. Since the modulus of elasticity obtained from LWD established a susceptibility criterion for collapsible soils thorough $\mathrm{K}_{\mathrm{LWD}}$ coefficient: high to $\mathrm{K}_{\mathrm{LWD}}>4.20$, low to $\mathrm{K}_{\mathrm{LWD}}<2.80$ and average for $\mathrm{K}_{\mathrm{LWD}}$ between 2.80 and 4.20. There is good correlation between the deflection
\end{abstract}


obtained with the LWD and displacements by blow obtained from the DPL, observing that when the deflection is low, the penetration rate is low, demonstrating greater stiffness of the soil.

Keywords: collapsible soil, LWD, DPL and susceptibility criterion.

\section{INTRODUÇÃO}

Na natureza, solos não saturados são encontrados em diversas condições. Em climas áridos e semi-áridos, dados de observações de campo de muitas décadas mostram que a variação de umidade com a profundidade não atinge a condição de saturação. Em clima onde a evapotranspiração excede a infiltração, a variação de deformação volumétrica depende da mudança de umidade e da condição de distribuição de ar nos seus vazios. $\mathrm{O}$ solo não saturado colapsível experimenta um radical rearranjo de partículas e grande redução de volume quando inundado com ou sem carga adicional [1]. Os solos colapsíveis podem ser considerados como "Solo Verdadeiramente Colapsível" quando não suportam seu próprio peso quando saturados e entram em colapso e "Solos Condicionados ao Colapso", quando são capazes de suportar certo nível de tensão após saturação [2].

Solos colapsíveis são encontrados em depósitos eólicos, aluviais, coluviais, em solos residuais e vulcânicos. São caracterizados por apresentarem uma estrutura porosa, potencialmente instável, baixo teor de água, agentes cimentantes que estabilizam os contatos intergranulares, mas são enfraquecidos durante o umedecimento [2].

São encontrados em muitas partes do mundo, tais como: Estados Unidos da América, Brasil, Argentina, Uruguai, Espanha, Austrália, Kuwait, Egito, Irã, África do Sul e China, particularmente em regiões áridas, semi-áridas e tropicais [3, 4]. A maioria dos solos colapsíveis encontrados nestas regiões são formados de depósitos eólicos e aluvionares $[5,6,7,8]$. Solos residuais de granitos foram encontrados na África do Sul e residuais de arenito nos Estados Unidos [3,8]. A formação da estrutura porosa nos solos residuais é derivada da lixiviação do material solúvel e colóides, [1,9].

No Brasil, ocorrem em diversos Estados: Amazonas, Piauí, Ceará, Pernambuco, Bahia, Minas Gerais, Tocantins, São Paulo, Paraná, Santa Catarina e Rio Grande do Sul e no Distrito Federal. Solos colapsíveis já foram encontrados em Petrolina-PE em vários locais associados a obras de infraestruturas e conjunto habitacionais: $[10,11,12,13,14,15]$. Cerca de $50 \%$ dos solos superficiais do município apresentam suscetibilidade alta ou média de ocorrência desses solos [13]. Vários danos já foram causados nessas edificações com prejuízo socioeconômico.

Os danos nas edificações podem ser evitados se na fase do projeto os solos colapsíveis forem identificados de forma adequada, avaliando-se as deformações adicionais e a redução de capacidade de suporte do solo devido à variação de umidade. Este artigo avalia a variação do volume, resistência de ponta e o modulo de elasticidade devido à mudança de umidade em um solo colapsível, aluvionar, do nordeste do Brasil, no Semi-árido de Pernambuco, na cidade de Petrolina. Além disso, estabelece um critério de suscetibilidade ao colapso através do ensaio com o Light Weight Deflectometer - LWD. Trata-se de uma análise feita por um equipamento moderno, de fácil operação e que fornece resultados imediatos após o teste, permitindo uma avaliação rápida em campo. É muito utilizado no controle de compactação em obras rodoviárias, buscou-se aqui também utilizando o LWD avaliar o comportamento do solo colapsível em campo na condição natural e devido à mudança de umidade.

\section{MATERIAIS E MÉTODOS}

O programa de investigação geotécnica desenvolvido em laboratório constou de ensaios para avaliar a caracterização física, química, a colapsibilidade por meio de ensaios edométricos simples e duplos e a caracterização microestrutural antes e depois do colapso. Em campo o programa constou de: sondagens de simples reconhecimento com determinação do $\mathrm{N}_{\mathrm{SPT}}$; coleta de amostras deformadas e indeformadas (tipo bloco) na profundidade de $0,80 \mathrm{~m}$ a $1,20 \mathrm{~m}$; ensaios para avaliar a resistência de ponta por meio dos Penetrômetros Estático (PE - cone) e Dinâmico Ligeiro (Dynamic Probing Light - DPL), o Módulo de Elasticidade Dinâmico por meio do Light Weight Deflectometer - LWD e a colapsibilidade por meio do Expansocolapsômetro em solo natural e inundado.

\subsection{Caracterização Física, Química e Microestrutural}

$\mathrm{Na}$ caracterização física do solo a preparação das amostras seguiu as recomendações da ABNT [16] e foram realizados os seguintes ensaios: Análise granulométrica, ABNT [17]; Massa específica dos grãos dos solos, ABNT [18]; Limite de liquidez, ABNT [19]; Limite de plasticidade, ABNT [20] e Ensaio de compactação, ABNT [21]. 
A caracterização química foi realizada para obter a classificação pedológica do solo seguindo as recomendações do Manual de Métodos de Análise de Solos [22].

A microestrutura do solo antes e após o colapso foi obtida por meio do Microscópio Eletrônico de Varredura (MEV). Duas amostras foram utilizadas em condições distintas: a primeira indeformada e a segunda obtida a partir do corpo de prova do ensaio edométrico simples, carregado e inundado na tensão vertical de consolidação que apresentou o maior valor de colapso (160 kPa ) e posterior descarregamento e secagem.

Na preparação da amostra indeformada para ser observada no MEV no estado natural foi necessário apenas coloca em um dessecador e submetê-la a um pequeno vácuo por se encontrar em baixa umidade. Foram realizadas várias pesagens até ocorrer constância de peso. Na amostra após carregamento, inundação e colapso, sob a tensão de $160 \mathrm{kPa}$ foi removido o excesso d'água da célula, através de uma pequena bomba de sucção manual e, posteriormente, com uso de incidência de luz (150 Watt) por 4 dias na célula. $\mathrm{O}$ solo foi descarregado e o anel com o solo foi colocado em dessecador com silica-gel, quando foram realizadas pesagens sucessivas para verificar constância de peso, caracterizando o processo de secagem. Procedimento similar foi realizado por Ferreira [5].

Para observar a microestrutura é necessário que amostras de solos estejam preservadas. Entretanto, o uso da Microscopia Eletrônica de Varredura requer um conjunto de condições (corte, secagem, superfície de observação com topografia não muito acidentada e uniformidade na metalização) que alteram a superfície de observação. Para se minimizar estes efeitos e obter uma superfície menos acidentada e com menor perturbação foram utilizadas as técnicas de descascamento e ou faturamento [23,5]. Pequenos instrumentos cortantes e outros pontiagudos auxiliaram nas fragmentações sucessivas das amostras, procurando deixar sempre superfícies em que os instrumentos não tivessem tocado. A forma final das amostras aproximou-se de um cubo com "arestas" que variaram de 7 a $10 \mathrm{~mm}$.

As amostras assim preparadas foram fixadas em um suporte de alumínio de formato cilíndrico. Em seguidas foram metalizadas e observadas no microscópio com uma máquina fotográfica acoplada ao equipamento.

\subsection{Caracterização da Colapsibilidade}

Foram realizados ensaios edométricos simples em amostras indeformadas do tipo bloco. As tensões aplicadas nos ensaios eram acrescidas de $\Delta \sigma / \sigma=1$, iniciando com $10 \mathrm{kPa}$ e finalizando com $1280 \mathrm{kPa}$. Como o solo era muito arenoso e as deformações após a aplicação das cargas imediatas, o tempo de duração de cada estágio de tensão era tal que a deformação entre dois intervalos de tempo consecutivos $(\Delta t / t=1)$ fosse inferior a $5 \%$ da deformação total do solo ocorrida até o tempo anterior [5,12]. Quando essa condição ocorria antes de 60 minutos deixava-se uma hora para adicionar-se o novo incremento de tensão, entretanto na tensão em que o solo foi inundado o tempo de duração do último estágio era 24 horas. As tensões de inundação foram 10; 20; $40 ; 80 ; 160 ; 320,640$ e $1280 \mathrm{kPa}$ afim de simular em laboratório as tensões transmitidas pelas edificações, pelas obras de artes projetadas e caracterizar qual a tensão crítica para o colapso máximo. Na fase de inundação, a entrada do permeante na célula era controlada por meio de uma bureta graduada de $0,1 \mathrm{ml}$, com uma torneira regulável de vidro em sua extremidade. O permeante utilizado nos ensaios foi água destilada e a vazão de inundação foi de $1,0 \mathrm{ml} / \mathrm{s}$. Os deslocamentos devidos à inundação eram medidos nos tempos de 0 ; 0,$10 ; 0,25 ; 1,00 ; 2,00 ; 4,00 ; 8,00 ; 15,00 ; 30,00 ; 60,00 ; 120,00 ; 480,00$ e 1440 minutos. Para a avaliação do potencial de colapso (CP \%) utilizou-se a Equação 1, proposta por Jennings e Knight [24].

$$
\mathrm{CP}(\%)=100 \Delta \mathrm{H} / \mathrm{Hi} \%
$$

Onde: $\mathrm{CP}$ é o potencial de colapso; $\Delta \mathrm{H}$ é a variação da altura do corpo de prova devido à inundação; Hi é a altura do corpo de prova antes da inundação.

Nos ensaios edométricos duplos, um corpo de prova foi carregado na umidade natural e o outro foi inundado previamente na tensão de $1,25 \mathrm{kPa}$, antes de ser carregado. O procedimento geral destes ensaios foi o mesmo dos ensaios edométricos simples. As tensões aplicadas nos ensaios durante o carregamento foram da mesma maneira que as tensões nos ensaios edométricos simples $(\Delta \sigma / \sigma=1)$, sendo o valor inicial de 10 $\mathrm{kPa}$ e o final de $1280 \mathrm{kPa}$. No descarregamento, as tensões por estágio foram 640; 160; $40 \mathrm{e} 10 \mathrm{kPa}$. O critério utilizado para definir o tempo de duração de cada estágio de tensão foi o mesmo do ensaio edométrico simples, entretanto para o corpo de prova inundado previamente esse tempo ocorria a 24 horas. 


\subsection{Investigação de Campo}

Foram realizados 12 furos de sondagens de simples reconhecimento seguindo as normas [25, 26, 27] da ABNT - Normas Gerais de Sondagem de Reconhecimento para Fundações de Edifícios, Método de Execução de Sondagem e Terminologia de Rochas e Solos, respectivamente. As sondagens foram realizadas até atingir o impenetrável (aproximadamente $10 \mathrm{a} 11 \mathrm{~m}$ ) e distribuídas nos locais das edificações dos blocos e das obras de artes.

\subsubsection{Avaliação da Resistência de Ponta pelos Penetrômetros Estático e Dinâmico}

A resistência à penetração foi avaliada com o penetrômetro estático (PE) utilizando um cone com área de $63300 \mathrm{~mm}^{2}$. O valor do deslocamento medido do anel (y, em $\mathrm{mm}$ ) foi transformado em força (kgf) pela equação de calibração do aparelho $(0,505 \mathrm{kgf} /$ divisão) que corresponde a uma resistência de ponta $\mathrm{Pq}=$ 0,00782y (MPa). A carga era aplicada por meio de um sistema de reação e macaco mecânico.

A resistência de ponta foi avaliada também pelo penetrômetro de impacto modelo IAA / PLANALSUCAR - STOLF, operado com ponta fina com área $=129 \mathrm{~mm}^{2}$. No solo com umidade natural foram realizados 7 furos afastados de $0,50 \mathrm{~m}$ e no solo inundado 5 furos afastados de $0,5 \mathrm{~m}$. $\mathrm{O}$ afastamento entre as verticais eram de $0,50 \mathrm{~m}$. A transformação dos valores da penetração da haste do aparelho no solo (cm/impacto) em resistência à penetração foi obtida pela fórmula dos "holandeses", segundo STOLF [28], Equação 2. O valor obtido do deslocamento foi transformado em kgf pela equação de calibração do aparelho, Equações 3, 4 e 5. Todos os ensaios foram realizados até a profundidade de 1,40 m.

A resistência de ponta foi avaliada no solo natural e inundado previamente. A inundação foi realizada fazendo um pré-furo e adicionando água por meio de uma tubulação que adicionava ao solo uma quantidade de água necessária para saturar uma espessura aproximadamente de 0,20 $\mathrm{m}$ do solo.

$$
\mathrm{RP}=\frac{\mathrm{Mg}+\mathrm{mg}+\left(\frac{\mathrm{M}}{\mathrm{M}+\mathrm{m}}\right) \frac{\mathrm{Mgh}}{\mathrm{x}}}{\mathrm{A}}
$$

Onde:

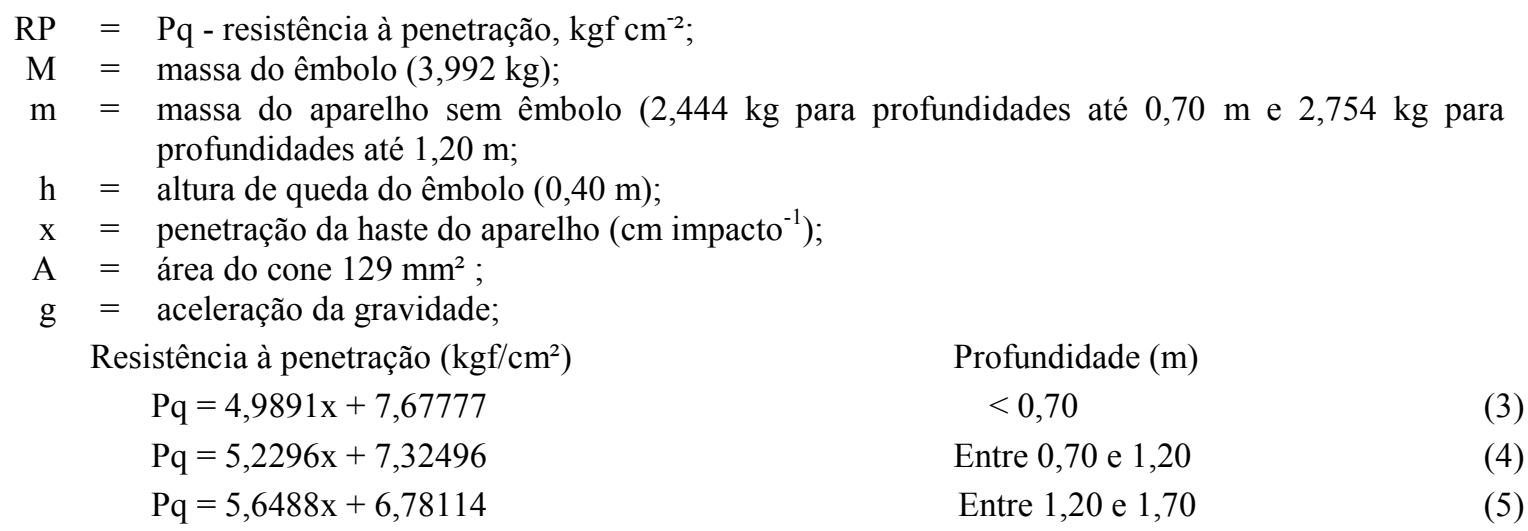

\subsubsection{Avaliação da Colapsibilidade pelo Expansocolapsômetro}

A avaliação do colapso devido à inundação em campo foi realizada com a $1^{\mathrm{a}}$ versão do Expansocolapsômetro, $[5,28]$. O diâmetro e a espessura da placa são $0,07 \mathrm{~m}$ e $0,01 \mathrm{~m}$, respectivamente. $\mathrm{O}$ sistema de aplicação de carga é composto dos pesos, viga de reação e colunas de estrutura metálica que fazem parte do sistema de mobilidade do próprio equipamento. A base do furo, a $0,50 \mathrm{~m}$ de profundidade, era limpa e nivelada com uma plainadeira. A placa e demais peças componentes do equipamento eram colocadas para atingir a profundidade do ensaio. Através do sistema de transferência de carga a placa, o carregamento era aplicado em estágio até atingir a tensão de inundação desejada (10 kPa, $20 \mathrm{kPa}, 40 \mathrm{kPa}, 80 \mathrm{kPa}$ e $160 \mathrm{kPa})$. Os deslocamentos eram aferidos por dois deflectômetros colocados diametralmente opostos com sensibilidade de 0,01 mm. O tempo de duração de cada estágio era tal que a diferença entre duas leituras de deformação consecutivas fosse inferior a $5 \%$ da deformação total ocorrida até aquele momento, com intervalos entre duas leituras consecutivas de $\Delta \mathrm{t} / \mathrm{t}=1$, mesmo critério utilizado nos ensaios edométricos simples. Quando os deslocamentos estabilizavam, inundava-se o solo com água a uma vazão de inundação de 1,0 ml/s, e medidos os deslocamentos causados pela variação de umidade no solo, até a sua estabilização. Após o término dos ensaios determinavam-se as umidades dos solos, a partir da base do furo, a cada 0,05 $\mathrm{m}$. 
2.3.3 Avaliação do Módulo de Elasticidade Dinâmico avaliado pelo Light Weight Deflectometer - LWD

O módulo de elasticidade dinâmico foi obtido por meio de ensaio de carga dinâmica em placa através do LWD, conforme apresentada na Figura 1a. A carga de impacto é causada por uma queda da massa sobre uma placa com um diâmetro de $0,30 \mathrm{~m}$, o que gera uma força máxima $\left(\mathrm{F}_{\text {máx }}\right)$ de $7,070 \mathrm{kN}$ e 10,6 kN para os pesos de $10 \mathrm{kgf}$ e de $15 \mathrm{kgf}$, respectivamente. A altura de queda do peso é de $0,715 \mathrm{~m}$. Durante calibração do dispositivo, esta força é ajustada de modo que a tensão normal $\left(\sigma_{\text {máx }}\right)$ sob a placa chega a $0,1 \mathrm{MN} / \mathrm{m}^{2}$ para o peso de $10 \mathrm{kgf}$ e de $0,15 \mathrm{MN} / \mathrm{m}^{2}$ para o peso de $15 \mathrm{kgf}$. Segundo a TP BF-StB Part B 8.3 [30], o módulo de elasticidade $\mathrm{E}_{\mathrm{LWD}}$ é um parâmetro de deformabilidade do solo sob uma carga de impacto vertical e seu valor é calculado em função da amplitude dos deslocamentos medidos de acordo com a Equação 6.

$$
\mathrm{E}_{\mathrm{LWD}}=1,5 \mathrm{r} \frac{\sigma_{\mathrm{máx}}}{\mathrm{s}_{\text {máx }}}
$$

Onde: $s_{\text {máx }}$ significa os valores das deflexões $s 4_{\text {máx }}, \mathrm{s} 5_{\text {máx }}$ e $s 6_{\text {máx }}$ dos 3 ensaios (após os três testes de pré-carregamento), r é o raio da placa de carga $(0,15 \mathrm{~m})$ e $\sigma_{\text {máx }}$ é a tensão normal sob a placa de carga $(0,1$ $\mathrm{MN} / \mathrm{m}^{2}$ ou $\left.0,15 \mathrm{MN} / \mathrm{m}^{2}\right)$.

O equipamento LWD é muito utilizado para medir as deflexões nas camadas compactas das bases dos pavimentos. Além do módulo de elasticidade, informa a deflexão média (s), a velocidade média (v) e o grau de compactabilidade ( $\mathrm{s} / \mathrm{v}$ ) através da relação entre a deflexão média. Se o valor de s/v for $>3,5$ o solo compactado necessita de compactação adicional ou ser substituído por outro [29].

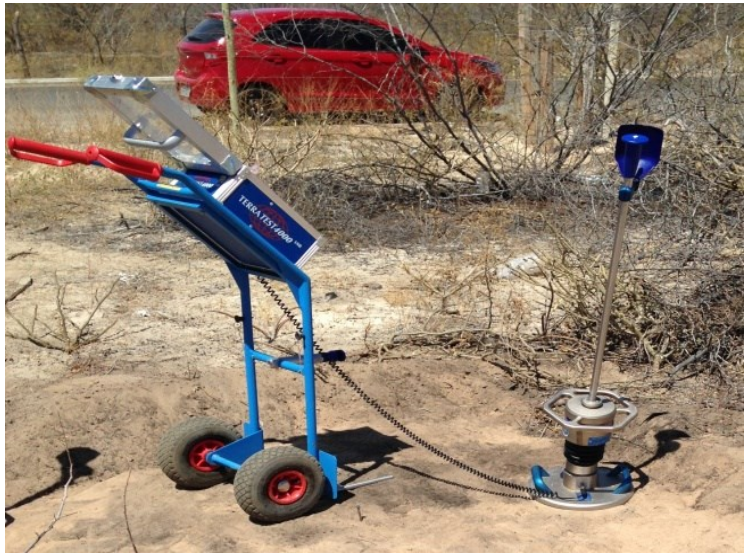

(a)
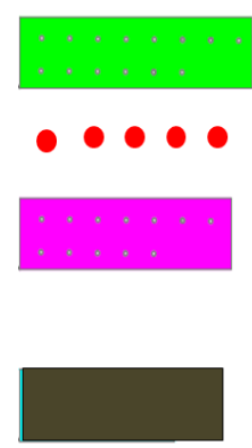

LEGENDA:

- eXPANSOCOLAPSOMETRO

- LWD

ENSAIO PENETROMETRO ESTÁTICO

ENSAIO PENETROMETRO DINÅMICO

POÇO - COLETA DE AMOSTRAS

SEM ESCALA

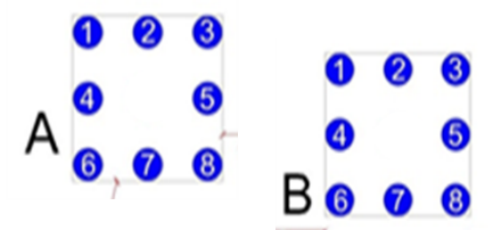

(b)

Figura 1: Ensaio com o LWD: (a) TERRATEST 4000 USB e (b) representação esquemática dos ensaios de campo.

O ensaio foi realizado com o seguinte procedimento: a placa de carga é colocada ao solo de modo a garantir o pleno contato; o dispositivo de carregamento é colocado no centro da placa e acoplado ao computador de teste; verifica-se a verticalidade e o ensaio pode ser inicializado. A carga de impacto é solta em queda livre de uma altura de $0,715 \mathrm{~m}$ por 03 (três) vezes referentes ao pré-carregamento e 03 (três) quedas referentes ao ensaio propriamente dito, medindo-se as deflexões.

O módulo de elasticidade dinâmico foi avaliado em duas áreas com dimensões de 2,0 m x 2,0 m, conforme apresentada na Figura $1 \mathrm{~b}$. Na Área foi realizado no solo na umidade natural a $0,30 \mathrm{~m}$ de profundidade e na Área B a $0,05 \mathrm{~m}$ de profundidade, sendo o solo inundado previamente de forma lenta e progressiva de modo a se obter uma umidade uniforme próxima à umidade de saturação, em uma espessura de 0,40 m (profundidade de influência do carregamento do impacto) [29], avaliada antes da realização do ensaio. Nas Áreas A e B foram realizados 32 ensaios no total, sendo que para cada área, 8 (oito) ensaios foram realizados com carga de impacto de $10 \mathrm{kgf} \mathrm{e}$, em seguida, mais 8 (oito) ensaios foram realizados com carga de impacto de $15 \mathrm{kgf}$.

\section{RESULTADOS E DISCUSSÃO}

Serão apresentados e discutidos os resultados obtidos nos ensaios de laboratório e campo. Serão abordadas: a caracterização física e química do solo de Petrolina-PE, colapsibilidade, miscroestrutura antes e após colapso, avaliação da resistência de ponta, avaliação do módulo de elasticidade e correlação LWD e DPL. 


\subsection{Caracterização Física e Química do solo}

O solo é essencialmente arenoso com mais de $90 \%$ de areia, com fração argilosa $<5 \%$ e praticamente sem silte (no máximo 2\%). O solo é mal graduado $\left(\mathrm{Cu}<5 \%\right.$ ), o valor do peso específico dos grãos é $26,32 \mathrm{kN} / \mathrm{m}^{3}$, é não líquido, não plástico e se enquadra no grupo SM, Areia Siltosa, na classificação do SUCS. O peso específico natural do solo varia de 14,97 a $15,10 \mathrm{kN} / \mathrm{m}^{3}$, os valores da umidade natural e do grau de saturação natural são $0,81 \%$ e $2,86 \%$, respectivamente, resultando em elevada sucção da ordem de 5,0 $\mathrm{MPa}$, o que confere ao solo uma rigidez significativa. O valor do peso específico aparente seco máximo é de $18,50 \mathrm{kN} / \mathrm{m}^{3}$ e umidade ótima de 7,30\%. Considerando o grau de compactação médio de $81 \%$ e desvio de umidade em relação a umidade ótima de - 6,49\% o solo é considerado colapsível pelos critérios do USBR [31] e de Vilar e Rodrigues [32].

Os resultados da caracterização química do solo obtidos nos ensaios realizados em seis amostras são apresentados na Tabela 1. A caracterização química do solo natural é ácido $(\mathrm{pH}<7)$. O valor do $\mathrm{pH} \mathrm{em}$ Cloreto de Potássio $\left(\mathrm{pH}_{\mathrm{KCl}}\right)$ é inferior ao valor do $\mathrm{pH}$ em água $\left(\mathrm{pH}_{\mathrm{H} 2 \mathrm{O}}\right)$ e, portanto, a variação do $\mathrm{pH}(\Delta \mathrm{pH}=$ $\mathrm{pH}_{\mathrm{KCl}}-\mathrm{pH}_{\mathrm{H} 2 \mathrm{O}}$ ) é negativa, indicando a presença de argilas silicatadas. A quantidade da matéria orgânica obtida a partir do carbono orgânico é baixa (menor que 1,0 \%). A capacidade de troca catiônica é baixa (valor $\mathrm{T}=\mathrm{CTC}<27 \mathrm{cmol}_{\mathrm{c}} \mathrm{kg}^{-1}$ ), indicando também a predominância do mineral argílico caulinita. A Saturação por base expressa em porcentagem (valor V) é inferior a 50\% tratando-se de um solo Distrófico. A porcentagem de sódio no complexo de trocável é baixa $\left(100 \mathrm{Na}^{+} \mathrm{T}^{-1}<6 \%\right)$ e cresce com a profundidade. A condutividade elétrica do extrato (CE) de saturação é alta, $>4 \mu \mathrm{S} / \mathrm{cm} / 25^{\circ} \mathrm{C}$ e decresce com a profundidade. Levando em consideração as características acima descritas e as características macromorfológicas do perfil de solo, conclui que o solo se enquadra na classe pedológica Neossolo Quartzorênico, com horizonte A fraco, textura arenosa fina, fase Caatinga hiperxerófila e relevo plano, típica de solo de origem aluvionar.

Tabela 1: Caracterização química do solo.

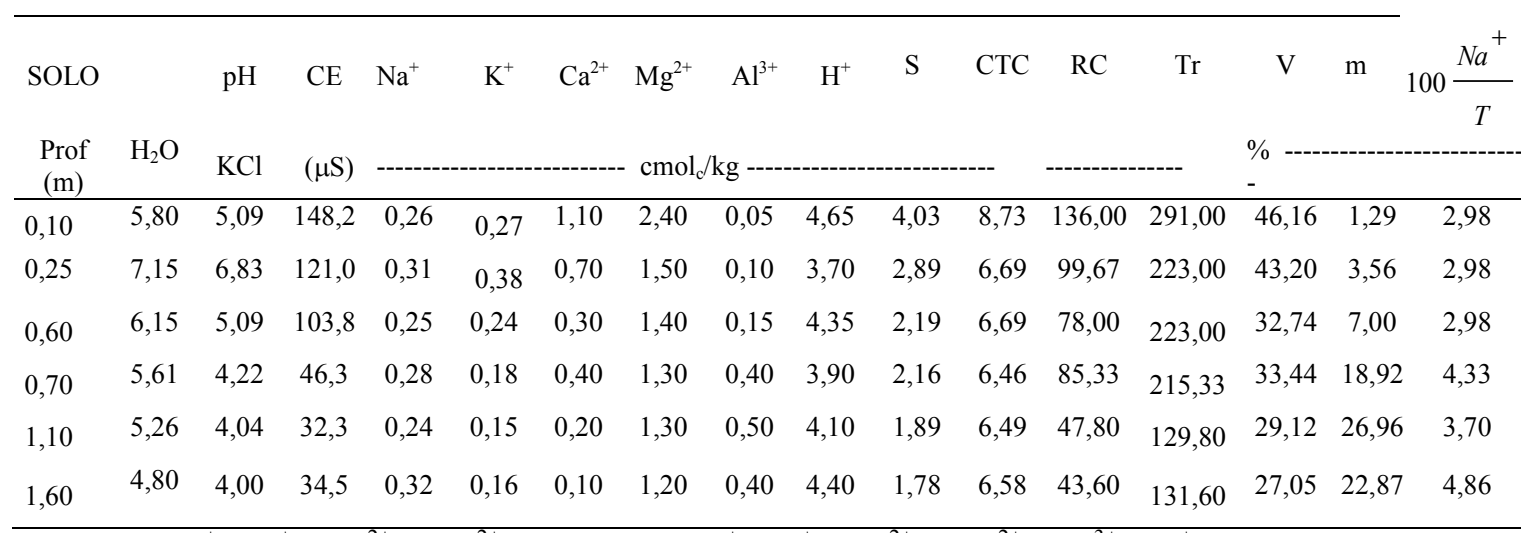

Onde: $\mathrm{S}=\mathrm{Na}^{+}+\mathrm{K}^{+}+\mathrm{Ca}^{2+}+\mathrm{Mg}^{2+} ; \mathrm{CTC}(\mathrm{T})=\mathrm{Na}^{+}+\mathrm{K}^{+}+\mathrm{Ca}^{2+}+\mathrm{Mg}^{2+}+\mathrm{Al}^{3+}+\mathrm{H}^{+}$;

$R C=100 \frac{S+A l^{3+}}{\arg i l a(\%)} ; \operatorname{Tr}=100 \frac{\mathrm{CTC}}{\operatorname{argila}(\%)} ; V=100 \frac{S}{T} ; m=\frac{100 A l^{3+}}{S+A l^{3+}}$

$\mathrm{Na}$ - sódio; $\mathrm{K}$ - potássio $\mathrm{Ca}$ - cálcio; $\mathrm{Mg}$ - magnésio; $\mathrm{Al}$ - alumínio $\mathrm{H}$ - hidrogênio; $\mathrm{S}$ - soma de bases; CTC capacidade de troca de cátions; RC - Retenção de Cátions; Tr - Atividade da Fração Argila; V - saturação por bases; m - Saturação por Alumínio.

\subsection{Caracterização da colapsibilidade do solo}

Os resultados dos ensaios edométricos simples e duplos e os valores dos potenciais de colapso para as tensões verticais de inundação são apresentadas na Figura 2. Os valores dos potenciais de colapso crescem atingindo um valor máximo de 4,58\% na tensão de $160 \mathrm{kPa}$ e depois decresce. Sendo esta, a tensão crítica para o colapso máximo, comportamento semelhante foi encontrado por [5, 14, 33]. Os valores dos potenciais de colapso (CP) são inferiores aos encontrados por Silva [13] no solo colapsível onde foi edificado o Conjunto Habitacional Privê Village - CHPV [13] e o Canal Pontal Azul - CPA [12], em Petrolina. Os valores das tensões geostática, de pré-consolidação nas condições de umidade natural e inundado previamente são respectivamente $15,10 \mathrm{kPa}, 95,00 \mathrm{kPa}$ e 19,00 kPa indicando que o solo é classificado como verdadeiramente colapsível pelo critério de Reginatto e Ferrero [2]. 
Os valores das deformações volumétricas específicas, obtidas em laboratório, através dos ensaios edométricos simples (Figura 3a), são superiores aos obtidos em campo com o Expansocolapsômetro (Figura 3b). Mesmo comportamento foi verificado em relação aos valores dos potenciais de colapso (Figura 3c).

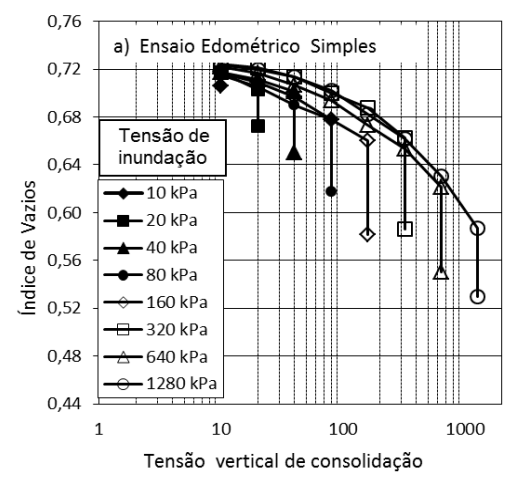

(a)

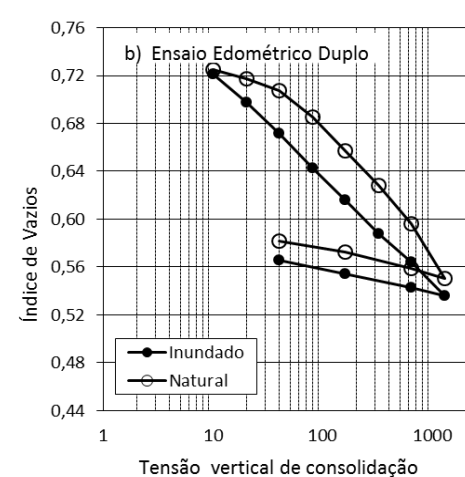

(b)

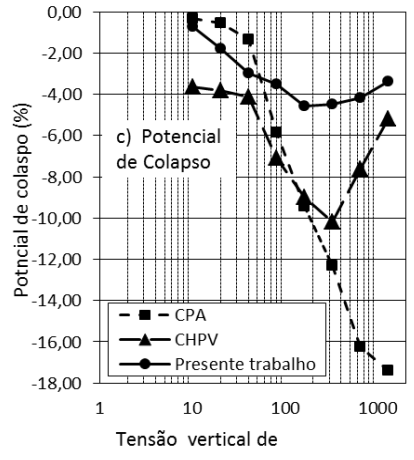

(c)

Figura 2: Resultados dos ensaios edométricos simples e duplo.

O processo de variação de volume devido à inundação em laboratório (Figura 4a) é mais rápido do que em campo (Figura 4b). Em laboratório $98 \%$ do processo ocorre a um minuto do início da inundação e em campo aos quatro minutos. Comportamento similar foi encontrado por Ferreira [5], Fucale [12] e Torres [15]. A diferença é atribuída ao caminho de percolação de água ser menor na amostra de laboratório do que no campo e a distribuição de tensão ser uniforme em toda a amostra em laboratório (amostra com $20 \mathrm{~mm}$ de altura), enquanto em campo é variável e decresce com a profundidade.

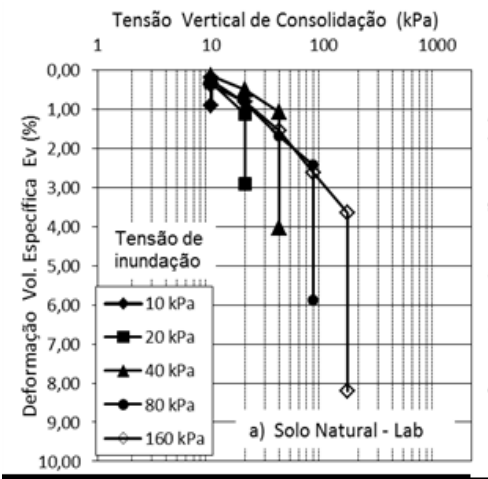

(a)

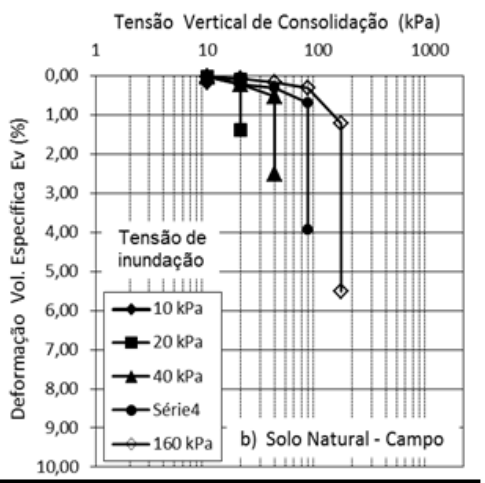

(b)

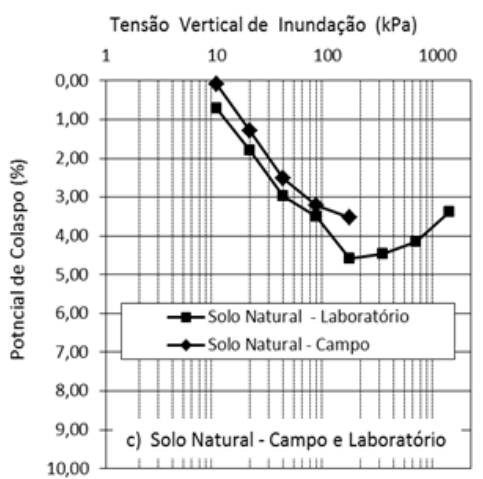

(c)

Figura 3: Curvas de deformação volumétrica específica e do potencial de colapso com a tensão vertical aplicada obtidas através de ensaios de laboratório e de campo.

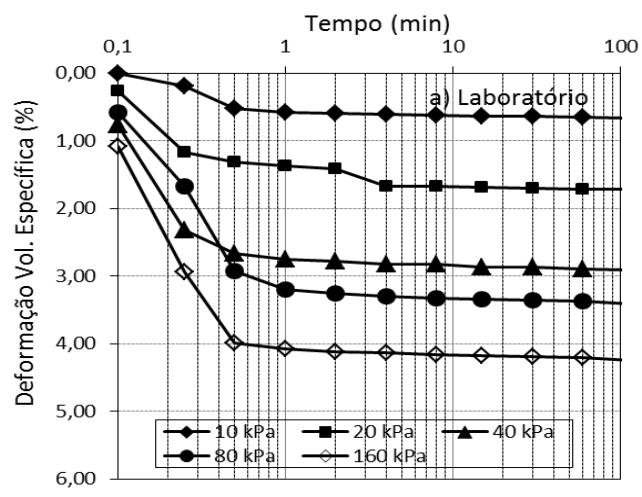

(a)

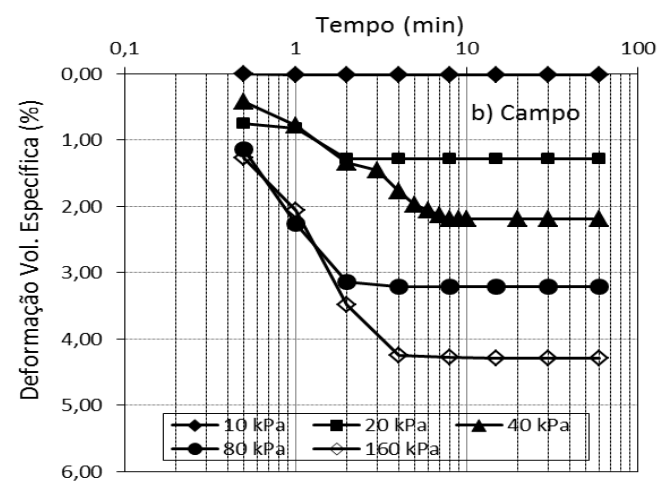

(b)

Figura 4: Curvas de deformações de colapso com o logaritmo do tempo a) Laboratório, b) Campo. 


\subsection{Microestrutura antes e após colapso}

O aumento de umidade em um solo colapsível estando carregado (Solo Condicionado ao Colapso) ou não (Solo Verdadeiramente Colapsível) pode apresentar uma variação brusca do volume e do rearranjo de sua estrutura. A microestrutura do solo natural é constituída por grãos de areia e pouca argila. Os grãos de areia são constituídos de quartzo, de tamanhos variados e de formas subarrendadas e angulares, conforme apresentada na Figura 5a. Os grãos encontram-se revestindo total ou parcialmente por argila, quase sempre não se estendendo ou formando pontes entre eles. Este tipo de microestrutura condiciona a formação predominante de um tipo de porosidade designada de empacotamento simples, BREWER [34].

O solo com índice de vazios inicial de 0,72 (indicado na Figura 5a pelo algarismo 1) comprimiu $2,07 \%$ sob a tensão vertical de $160 \mathrm{kPa}$, na mesma umidade inicial, porém, agora, com índice de vazios de 0,66 , grau de saturação de 3,23\% e peso específico aparente seco de $15,84 \mathrm{kN} / \mathrm{m}^{3}$ (indicado na Figura 5 a pelo algarismo 2), a inundação provocou um colapso de 4,58\% (esta condição é apresentada na Figura 5a com a indicação do algarismo 3). Após o processo de colapso, o solo foi dessecado sob a tensão de 160,00 kPa e descarregado à tensão zero com variação de volume positiva de $0,20 \%$. A amostra foi preparada para ser observada no MEV. Apesar de todos os efeitos do processo de preparação das amostras (secagem, alívio de tensão, corte, vácuo, etc), observa-se que a estrutura do solo após colapso é similar a do solo indeformado. Há, entretanto, um empacotamento mais denso entre os grãos, causado pela aplicação da tensão e do colapso (Figura 5e). A microestrutura do solo após colapso ainda é instável e os grãos de areia encontram-se ainda revestidos com argila iluvial. Comportamento similar observado no solo de Petrolândia-PE [5,35].
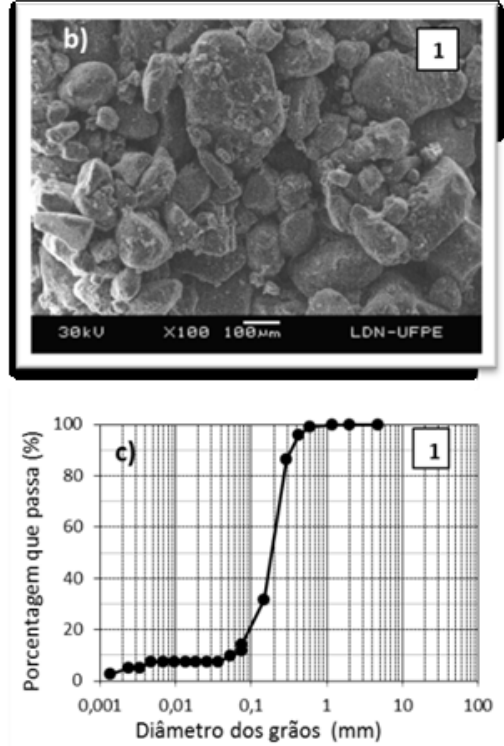
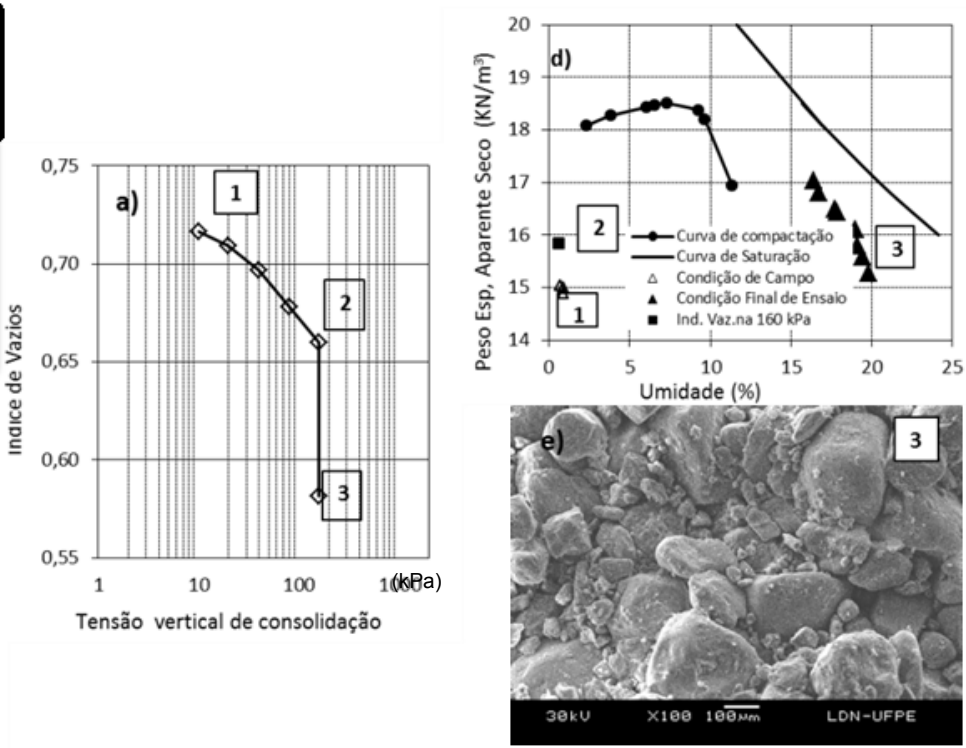

Figura 5: Variação do potencial de colapso associado ao estado tensão: a) Curva e x $\sigma \log$ - ensaio edométrico simples para tensão de inundação de $160 \mathrm{kPa}$, b) Microestrutura do solo natural, c) Distribuição dos grãos, d) Curva de compactação, e) Microestrutura do solo após colapso.

\subsection{Avaliação da Resistência de Ponta}

O perfil do solo de Petrolina até 9 metros de profundidade é constituído de duas camadas, uma areia fina siltosa de pouco a medianamente compacta, seguida de uma areia fina e média, de compacidade média a compacta, conforme apresentado na Figura 6a. Considerando os valores médios do índice de resistência à penetração (golpes $/ 0,3 \mathrm{~m}$ ) verificou-se que estes crescem com a profundidade $\left(\mathrm{N}_{\mathrm{SPT}}=1,5 \mathrm{Z}+3,6\right.$ com $\mathrm{R}^{2}=$ 0,91 e $Z$ em m), conforme apresentado na Figura 6b. Na profundidade de 9,5 m o impenetrável a percussão é atingido e o solo é um pedregulho com argila siltosa. 


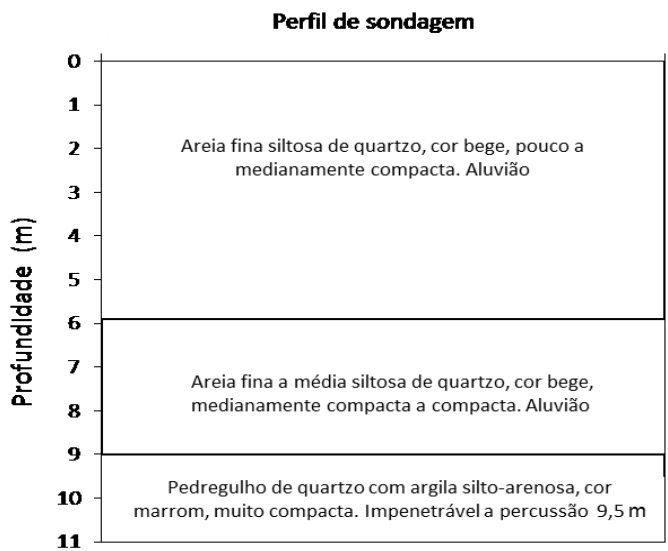

(a)

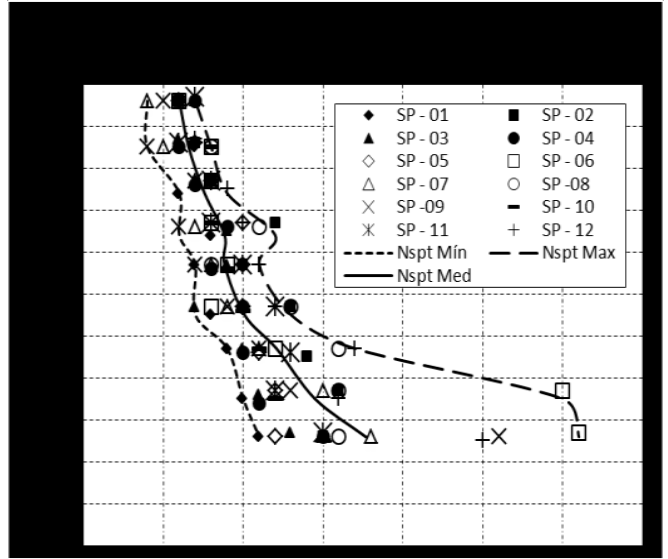

(b)

Figura 6: Perfil do solo.

Os valores da resistência de ponta $(\mathrm{Pq})$ no solo determinados com o penetrômetro estático até a profundidade de 1,40 m na umidade natural e inundado são mostrados nas Figuras 7a e 7b, respectivamente. A resistência de ponta no solo na umidade natural cresce linearmente com a profundidade até $0,20 \mathrm{~m}$ e para profundidades superiores varia de 1,0 a 1,5 Mpa, conforme apresentada na Figura $7 \mathrm{a}$. No solo inundado previamente, a resistência de ponta variou de 0,3 a 1,5 $\mathrm{MPa}$, sem evidências de crescimento com a profundidade, conforme apresentada na Figura $7 \mathrm{~b}$. A razão entre a resistência de ponta do solo na umidade natural e inundado $(\mathrm{Kw}=\mathrm{Pq} / \mathrm{Pqw})$ é variável com a profundidade, com valores próximos a 1 na superfície do terreno e chegando a 3,5 na profundidade de 1,40 m, Figura 7c. Considerando os valores médios, a relação $(\mathrm{Kw}=\mathrm{Pq} / \mathrm{Pqw})$ variou de 1,2 a 1,8 com a profundidade. Os valores de $\mathrm{Kw}$ encontrados neste estudo são muito próximos aos valores obtidos por Reznik [36], pelo qual utilizou resultados de ensaio de cone (CPT) em tensões inferiores às obtidas no presente trabalho.

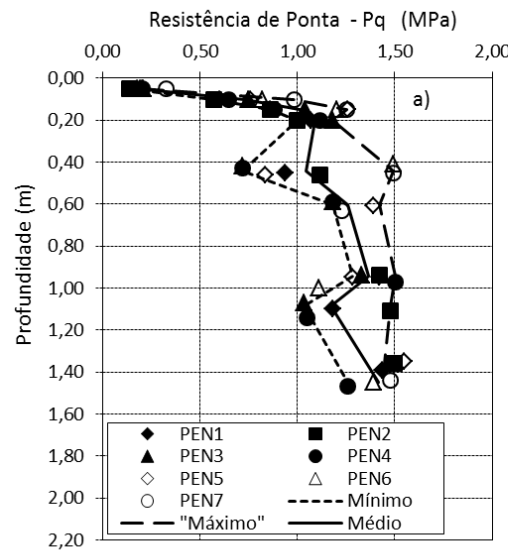

(a)

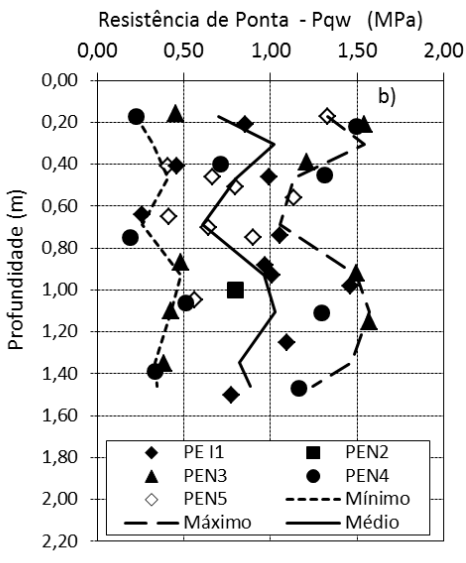

(b)

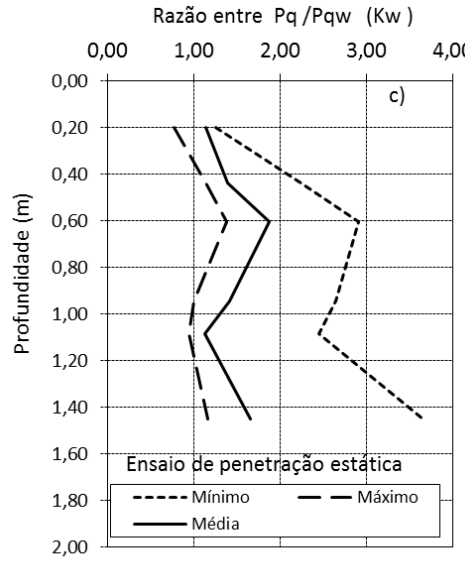

(c)

Figura 7: Resistência de Ponta obtida com Penetrômetro Estático: a) Solo natural, b) Solo inundado e c) Relação entre a Resistência de Ponta no solo natural e inundado.

Os valores da resistência de ponta $(\mathrm{Pq})$ determinados com o penetrômetro de Impacto - DPL no solo na umidade natural cresce com a profundidade (Figura 8a) e no solo inundado varia de 1 a $2 \mathrm{MPa}$ até $1,0 \mathrm{~m}$ de profundidade e de 1,2 a 3,0 MPa até a profundidade de 1,40 m (Figura 8b). Os valores da razão entre a resistência de ponta do solo na umidade natural e inundado $(\mathrm{Kw}=\mathrm{Pq} / \mathrm{Pqw})$ cresce com a profundidade, $\mathrm{Kw}$ $(\mathrm{MPa})=6 \mathrm{Z}(\mathrm{m})$, conforme apresentada na Figura 8c. 


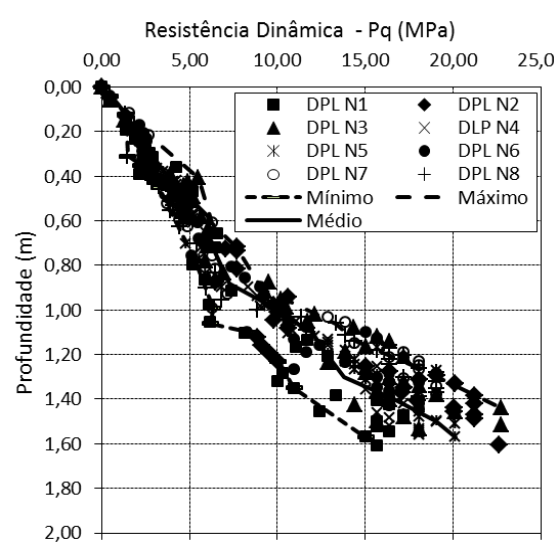

(a)

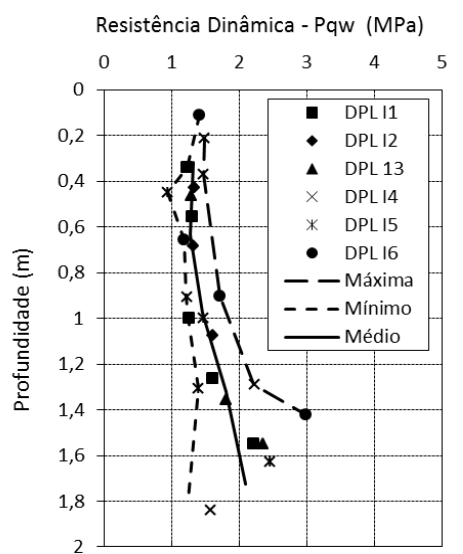

(b)

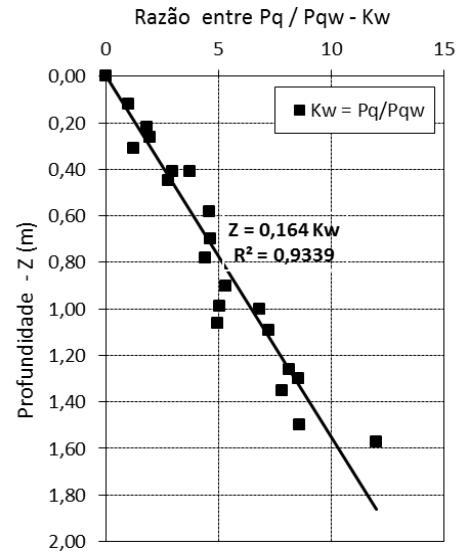

(c)

Figura 8: Resistência de Ponta obtida com Penetrômetro de Impacto (DPL): a) Solo natural, b) Solo inundado e c) Relação entre a Resistência de Ponta no solo natural e inundado.

\subsection{Avaliação do Módulo de Elasticidade}

A Figura 9 mostra as deflexões após impacto no solo na umidade natural e inundado previamente. No solo natural, as curvas individuais são sobrepostas (Figura 9a) enquanto que para o solo inundado previamente há distanciamento das 3 curvas individuais; assim como constata-se os maiores valores das deflexões (Figura $9 b)$. As deflexões no solo inundado previamente são 7,7 vezes maiores que as deflexões no solo natural. $O$ grau de compactabilidade (s/v) no solo natural é superior a 3 vezes a do solo inundado. Solos fofos ou poucos resistentes apresentam baixos valores de módulo de elasticidade e as três curvas individuais de deflexão apresentam afastamentos entre si [37]. Percebe-se que esse comportamento acontece no solo inundado (Figura 9b), pois a entrada de água no solo colapsível provoca a diminuição sucção e rigidez. O solo na umidade natural muito baixa associado a um módulo de elasticidade maior indica a uma maior rigidez e consequentemente menores deflexões, a inundação eleva a umidade, reduz a sucção, reduz o módulo de elasticidade e eleva as deflexões que crescem a medida que os impactos (cargas) são aplicadas. Portanto, através da análise das curvas de deflexões, é possível perceber o comportamento do solo quanto à perda da resistência quando submetido à inundação e aplicação de carga.

O solo colapsível na sua condição natural apresenta-se uma estrutura instável, porém com uma rigidez temporária devido a sucção elevada e/ou cimentação. Essa rigidez é que justifica as pequenas deflexões, maior módulo de elasticidade e a sobreposição das curvas individuais de deflexão (Figura 9a). Situação oposta acontece no solo inundado em que a rigidez temporária foi alterada pela entrada da água ocasionando a diminuição da sucção e/ou quebra das ligações cimentantes, resultando em um solo com menor rigidez. Assim, no solo inundado ocorrem maiores deflexões, menor módulo de elasticidade e os afastamentos entre as curvas individuais de deflexão (Figura 9b).

A Tabela 2 apresenta os valores dos módulos de elasticidade $\left(\mathrm{E}_{\mathrm{LWD}}\right)$ obtidos com o LWD. O solo inundado previamente apresenta valores bem menores que o solo na umidade natural, enquanto que as deflexões (s médio) apresentaram valores superiores. O módulo de elasticidade no solo natural varia de 46,3 a 79,2 MPa, enquanto no solo inundado, varia de 9,3 a 22,5 MPa. A inundação causa uma redução de $88 \%$ do nos valores dos módulos de elasticidade. 


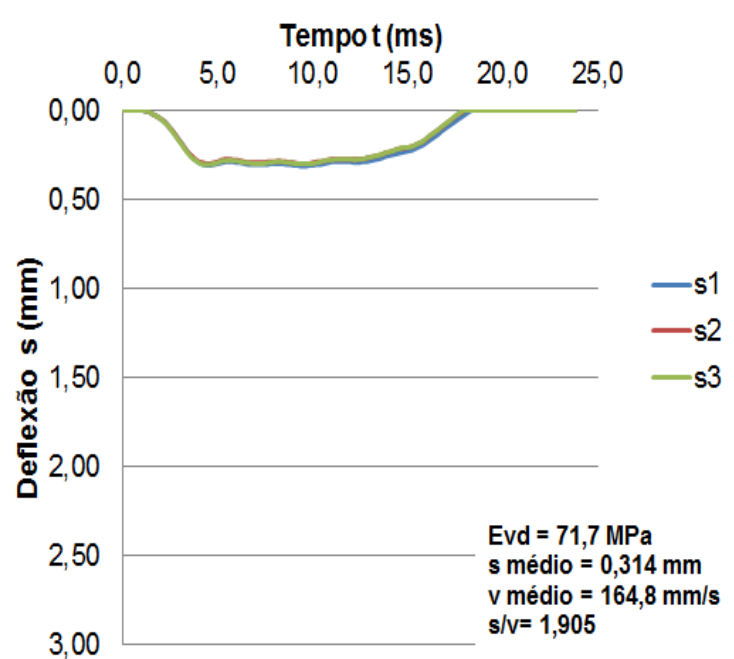

(a) Solo na umidade natural

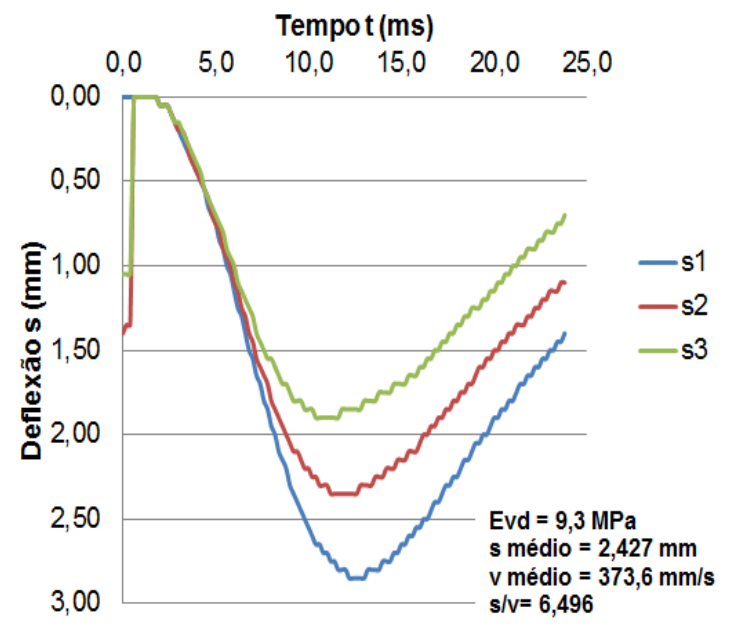

(b) Solo inundado previamente

Figura 9: Curvas de deflexões individuais para o solo na umidade natural e inundado previamente, ensaio realizado com peso de 10 kgf: (a) Ponto 6 da Área A e (b) Ponto 5 da Área B.

Tabela 2: Valores de módulo de elasticidade $\mathrm{E}_{\mathrm{LWD}}$, deflexão média e s/v para a situação do solo na condição natural e inundado.

\begin{tabular}{cccccc}
\hline Local & Peso & Valores & $\mathbf{E}_{\mathbf{L w D}}(\mathbf{M P a})$ & $\mathbf{s}$ médio $(\mathbf{m m})$ & $\mathbf{s} / \mathbf{v}(\mathbf{m s})$ \\
\hline \multirow{2}{*}{ Área A } & & Médio & 59,3 & 0,391 & 2,156 \\
(natural) & $10 \mathrm{kgf}$ & Mínimo & 46,3 & 0,284 & 1,872 \\
& & Máximo & 79,2 & 0,486 & 2,349 \\
Área B & & Médio & 16,1 & 1,509 & 5,425 \\
(inundado) & $10 \mathrm{kgf}$ & Mínimo & 9,3 & 1,000 & 3,907 \\
& & Máximo & 22,5 & 2,427 & 6,496 \\
Área A & & Médio & 55,8 & 0,616 & 2,256 \\
(natural) & $15 \mathrm{kgf}$ & Mínimo & 46,4 & 0,472 & 1,958 \\
& & Máximo & 71,5 & 0,727 & 2,604 \\
Área B & & Médio & 18,3 & 1,888 & 5,227 \\
(inundado) & $15 \mathrm{kgf}$ & Mínimo & 14,7 & 1,480 & 4,281 \\
& & Máximo & 22,8 & 2,297 & 5,786 \\
\hline
\end{tabular}

A Figura 10 mostra a variação dos valores das deflexões após impacto, utilizando o peso de 10,0 Kgf e posteriormente o peso de 15,0 Kgf na condição de umidade natural (Figura 10a) e no solo inundado previamente (Figura 10b). Tanto no solo natural como no solo inundado há um aumento das deflexões após o ensaio com o peso de $15 \mathrm{Kgf}$, como era de se esperar pelo fato do aumento do peso. Fazendo a comparação dos resultados apresentados nas Figuras 10a e 10b, observa-se, além do aumento das deflexões há diminuição no módulo de elasticidade, Tabela 2.

No solo natural, o acréscimo nos valores das deflexões devido ao acréscimo de carga foi de 57,54\%, enquanto que no solo inundado previamente o acréscimo foi menor, $25,12 \%$. Isto pode ser explicado pelo fato de que o solo inundado previamente sob o impacto da carga de $10 \mathrm{kgf}$ apresentou deflexões maiores (devido a carga e a inundação) do que no solo na umidade natural quando recebeu o impacto da carga de 15 kgf. No solo natural o grau de compactabilidade ( $\mathrm{s} / \mathrm{v}$ ) apresenta um pequeno crescimento $(4,6 \%)$ e no solo inundado previamente apresenta uma pequena diminuição $(3,7 \%)$. No solo na condição de inundada previamente o valor da relação $(\mathrm{s} / \mathrm{v})$ para as duas cargas de impacto foi $>3,5$ indicando que o solo precisa ser mais compactado ou substituído por outro [37]. 


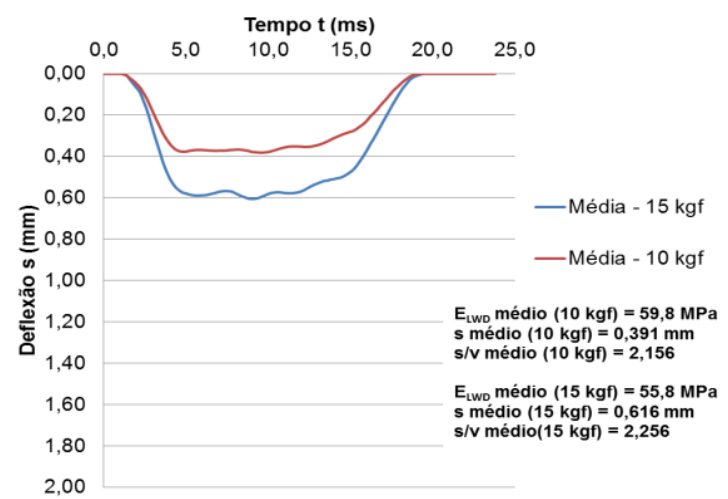

(a)

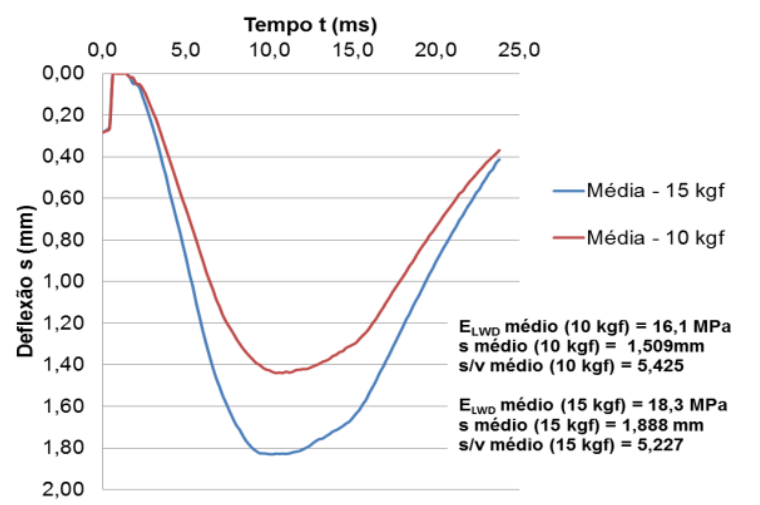

(b)

Figura 10: Deflexões devidas aos pesos de 10 kgf e 15 kgf: (a) Área A, solo natural e (b) Área B, solo inundado.

Definindo-se o coeficiente de colapsibilidade $\left(\mathrm{K}_{\mathrm{LWD}}\right)$ pela relação entre os módulos de elasticidade obtidos com o LWD, no solo natural e no solo inundado previamente é possível relacionar a instabilidade volumétrica. A Tabela 3 apresenta os resultados dos coeficientes $K_{L W D}$ obtidos pela Equação (7) a partir dos valores do módulo de elasticidade encontrados da Área A e na Área B, utilizando as cargas de impacto de 10 kgf e $15 \mathrm{kgf}$. Os valores do $\mathrm{K}_{\mathrm{LWD}}$ são maiores para a carga de impacto de $10 \mathrm{kgf}$ do que para a carga de 15 kgf. Deve-se ao fato de que o solo já havia comprimido e colapsado sob a carga de10 kgf quando a carga de $15 \mathrm{kgf}$ foi aplicada. Para estabelecer as faixas de valores representadas por cada nível de suscetibilidade, realizou-se a média dos 8 menores valores de $K_{L W D}$ e dos 8 maiores. Para valores menores do que a média dos menores valores foi atribuída a suscetibilidade baixa e para valores superiores a média dos maiores valores na suscetibilidade alta e aos valores intermediários a suscetibilidade média Portanto, a faixa de valores de $\mathrm{K}_{\mathrm{LWD}}$ e seus níveis de suscetibilidade ao colapso estão apresentados na Tabela 4.

$$
\mathrm{K}_{\mathrm{LWD}}=\frac{\mathrm{Eq}}{\mathrm{EW}}
$$

onde:

$\mathrm{K}_{\mathrm{LWD}}=$ coeficiente de colapso obtido com LWD;

$\mathrm{Eq}=$ módulo de elasticidade do LWD no solo natural, em $\mathrm{MPa}$;

$\mathrm{EW}=$ módulo de elasticidade do LWD no solo inundado, em MPa.

Tabela 3: Valores de $\mathrm{K}_{\mathrm{LWD}}$.

\begin{tabular}{c|c|c}
\hline Ponto de determinação & Área A e B (10 kgf) $\mathrm{K}_{\mathrm{LWD}}$ & Área A e B (15 kgf) $\mathrm{K}_{\mathrm{LWD}}$ \\
\hline 1 & 3,10 & 2,76 \\
2 & 2,90 & 3,10 \\
3 & 4,48 & 3,35 \\
4 & 4,95 & 3,79 \\
5 & 4,99 & 3,22 \\
6 & 4,33 & 2,76 \\
7 & 4,13 & 3,64 \\
8 & 2,24 & 2,17 \\
\hline
\end{tabular}

Tabela 4: Identificação de solos colapsíveis através do ensaio com LWD para o solo colapsível do município de Petrolina-PE.

\begin{tabular}{c|c}
\hline Faixa de valores de $\mathrm{K}_{\mathrm{LWD}} *$ & Nível de Suscetibilidade ao colapso \\
\hline $\mathrm{K}_{\mathrm{LWD}}<2,8$ & Baixo \\
$2,8<\mathrm{K}_{\mathrm{LWD}}<4,2$ & Médio \\
$\mathrm{K}_{\mathrm{LWD}}>4,2$ & Alto \\
\hline
\end{tabular}


*Valores obtidos em região de alta suscetibilidade ao colapso com base na carta elaborada por Silva [13].

\subsection{Correlação LWD e DPL}

A Figura 11 mostra as relações entre as deflexões (s - Figuras 11a e 11b) e os módulos de elasticidade ( $E_{L W D}$ -, Figuras 11c e 11d) obtidos através do LWD com os deslocamentos por golpes ( $\mathrm{I}_{\mathrm{DPL}} \mathrm{mm} / \mathrm{golpes}$ ) obtidos com o DPL no solo com a umidade natural (Figuras 11a e 11c) e no solo inundado previamente (Figuras $11 \mathrm{~b}$ e 11d). Nas correlações apresentadas consideraram as médias dos valores do $\mathrm{I}_{\mathrm{DPL}}$ correspondente as profundidades em que há influência de propagação do impacto no solo para as cargas aplicadas LWD. Esse valor é $0,40 \mathrm{~m}$ [37]. Os valores das deflexões (s) foram multiplicados por 10 para que os resultados não fossem muito pequenos, o que dificultaria a colocação nos gráficos.

Observar-se que quando a deflexão é baixa, o índice de penetração é baixo, demonstrando maior rigidez do solo. Ao menor índice de penetração e deflexão está associada maior a resistência. Na correlação com o módulo de elasticidade, verifica-se que quando o índice de penetração é baixo, o módulo de elasticidade é alto, ou seja, solo mais resistente. Assim tanto na correlação entre $\mathrm{s} x \mathrm{I}_{\mathrm{DPL}}$ quanto na $\mathrm{E}_{\mathrm{LWD}} \mathrm{x}$ $\mathrm{I}_{\mathrm{DPL}}$, os resultados demonstraram uma tendência já esperada. Apesar da natureza das propriedades mensuradas serem diferentes, uma resposta de deformabilidade (LWD) e a outra de ruptura por cisalhamento (DPL), os resultados demonstraram boas correlações. Os resultados obtidos para s x $\mathrm{I}_{\mathrm{DPL}}$ apresentaram uma boa correlação positiva ( $\mathrm{R}$ próximo de 1 ), enquanto que $\mathrm{E}_{\mathrm{LWD}} \times \mathrm{I}_{\mathrm{DPL}}$ apresentaram uma boa correlação negativa (R próximo de -1), conforme apresentado na Figura 11.

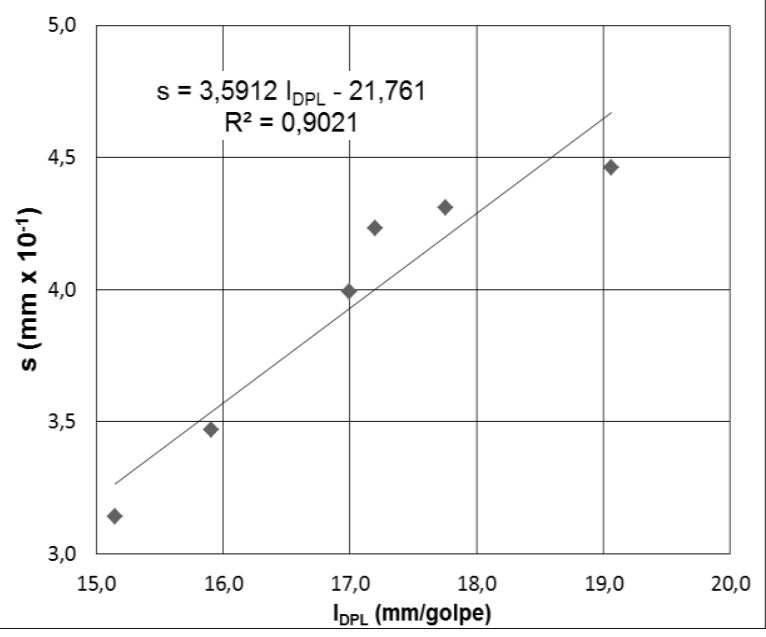

(a) Solo natural e carga de impacto $10 \mathrm{kgf}$

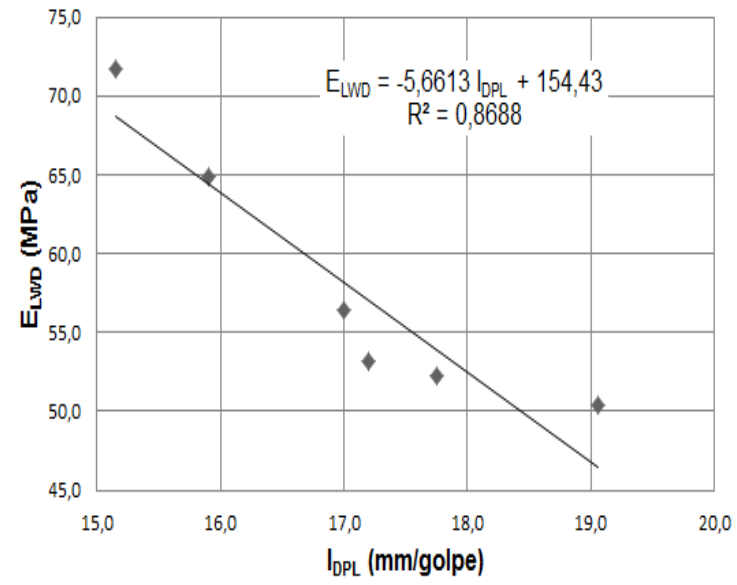

(c) Solo natural e carga de impacto $10 \mathrm{kgf}$

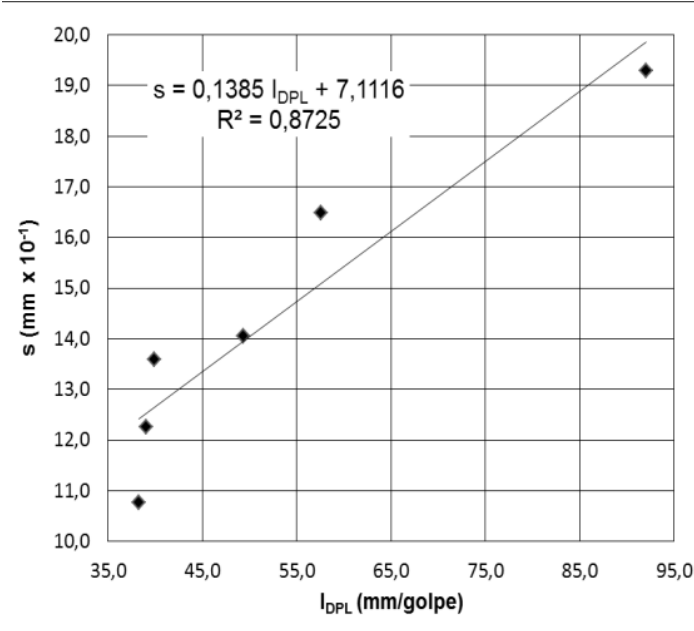

(b) Solo inundado e carga de impacto $10 \mathrm{kgf}$

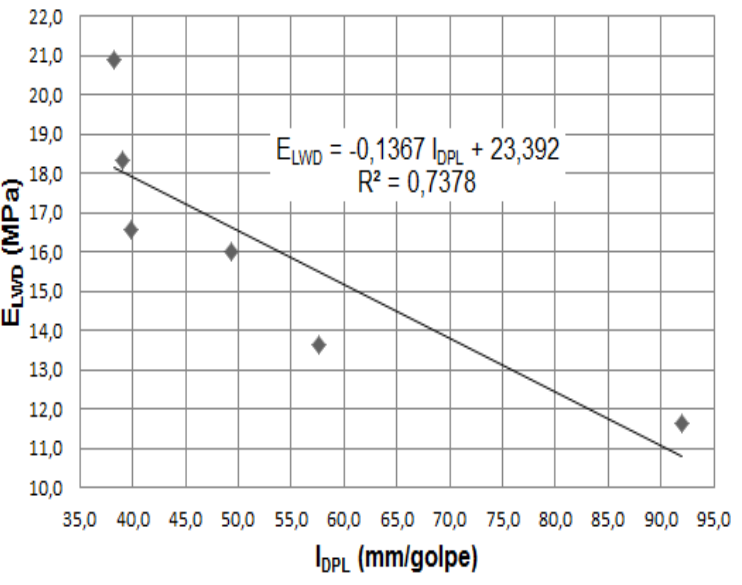

(d) Solo inundado e carga de impacto $10 \mathrm{kgf}$

Figura 11: Relações entre as deflexões (s) e os módulos de elasticidade $\left(\mathrm{E}_{\mathrm{LWD}}\right)$ obtidos através do LWD, carga de impacto $10 \mathrm{kgf}$, com o deslocamento por golpe ( $\mathrm{I}_{\mathrm{DPL}}$ ) obtidos com o DPL: a) s x $\mathrm{I}_{\mathrm{DPL}}$ no solo na umidade natural; b) $\mathrm{s} x$ $\mathrm{I}_{\mathrm{DPL}}$ no solo inundado previamente; c) $\mathrm{E}_{\mathrm{LWD}} \times \mathrm{I}_{\mathrm{DPL}}$ no solo na umidade natural; d) $\mathrm{E}_{\mathrm{LWD}} \times \mathrm{I}_{\mathrm{DPL}}$ no inundado previamente. 
Observa-se que as correlações obtidas com o solo natural foram melhores do que com o solo inundado previamente. Isto se deve principalmente ao fato de que no solo natural a umidade era constante com a profundidade enquanto no solo inundado previamente, a inundação era realizada de cima para baixo havendo um gradiente de variação de umidade com a profundidade, como o valor considerado para as correlações foram os médios dos $0,40 \mathrm{~m}$ iniciais este fator influenciou na correlação.

\section{CONCLUSÕES}

O solo é verdadeiramente colapsível, apresenta comportamento de pico na relação entre o potencial de colapso e a tensão aplicada, ocorrendo o valor máximo para a tensão de $160 \mathrm{kPa}$ e a microestrutura após colapso ainda é instável.

O colapso obtido em campo, com o Expansocolapsômetro, é inferior ao obtido em laboratório, com ensaio edométrico simples e o colapso ocorre mais rapidamente em laboratório do que em campo. Isto se deve a distribuição de tensão ser uniforme em todo o corpo de prova em laboratório e é variável com a profundidade em campo.

Os resultados obtidos com o LWD demonstraram que o aumento da umidade associada à aplicação da carga dinâmica causa uma redução de sua rigidez, ocorrendo uma diminuição do módulo de elasticidade e, consequentemente, um aumento da deflexão.

O módulo de elasticidade varia de 46,3 a $79,2 \mathrm{MPa}$ e a inundação causa uma redução de $88 \%$ desse parâmetro. As deflexões no solo inundado são 7,7 vezes maiores que as deflexões no solo natural.

O coeficiente de colapsibilidade $\left(\mathrm{K}_{\mathrm{LWD}}\right)$ definido pela relação entre os módulos de elasticidade obtidos com o LWD, no natural e no solo inundado previamente é um indicador da suscetibilidade ao colapso. Indicando alta para $\mathrm{K}_{\mathrm{LWD}}>4,20$, média para $\mathrm{K}_{\mathrm{LWD}}$ entre 2,8 e 4,20 e baixa para $\mathrm{K}_{\mathrm{LWD}}<2,8$.

Há boa correlação entre as deflexões obtidas com o LWD e o deslocamento por golpe obtido com o DPL.

\section{BIBLIOGRAFIA}

[1] VARGAS, M. "Earth dam foundations on porous soils”, In: Pro. III Nat'l Seminar on Lange Dams, São Paulo, Heavy Construction Magazine, pp. 77-81, 1972.

[2] REGINATTO, A.R, FERRERO, J.C. "Colapse potencial of soils and soil-water chemistry", In: Proceedings of the $8^{\text {th }}$ International Conference on Soil Mechanics and Foundation Engineering, v. 2 , pp.c177-183, Moscow, 1973.

[3] DUDLEY, J.H. "Review of collapsing soils", Journal of Geotechnical Engineering Division, v. 96, n.5, pp. 925-947, 1970.

[4] AL-RAWAS, A.A. "State-of-the-art review of collapsible soils", Science and Technology, Special Review, Sultan Qaboos University, pp. 115-135, 2000.

[5] FERREIRA, S.R.M. Colapso e expansão de solos naturais não saturados devidos à inundação, Tese de D. Sc., COPPE/UFRJ, Rio de Janeiro, RJ, Brasil, 1995.

[6] RAFIE, B.M.A., MOAYED, R.Z. ESMAELI, M. "Evaluation of soil collapsibility potential: A case study of Semnan railway station”, Electronic Journal of Geotechnical Engineering, v. 13, pp. 1-7, 2008.

[7] AYADAT, T., HANNA, A. H. "Assessement of soil collapse prediction methods", IJE Transactions B: Aplications, v.25 n.1 pp. 19-26, 2012

[8] CLEMENCE, S.P., FINBARR, A.O. "Design considerations for collapsible soils", Journal of the Geotechnical Engineering Division, American Society of Civil Engineers, v.107, pp. 305-307, 1981.

[9] JENNINGS, J.E., KNIGHT, K. "A guide to construction on or with materials exhibiting additional settlement due to a collapse of grain structure", In: Proceedings of the $4^{\text {th }}$ Regional Conference for Africa on Soil Mechanics and Foundation Engineering, pp. 99-105, Durban, 1975.

[10] MENDONÇA NETO, H.C., FERREIRA, S.R.M. "Behavior of volume change due to wetting in a collapsible soil to used in irrigation channel", Journal of Civil Engineering and Architecture., v.2, p.770 $778,2015$. 
[11] ARAGÃO, C. J. G.; MELO, A. C. de., "Fundações Rasas em solo colapsível: um caso no semi-árido de Pernambuco", In: VII Congresso Brasileiro de Mecânica dos Solos e Engenharia de Fundações, v. 2, pp. 1940, Olinda, 1982.

[12] FUCALE, S. P., Comportamento de variação de volume devido à inundação em alguns solos colapsiveis do estado de Pernambuco, Dissertação de Mestrado, UFPE, Recife, PE, Brasil, 2000.

[13] SILVA, M. J. R., Comportamento geomecânico de solos colapsiveis e expansivos em Petrolina-PE: cartas de suscetibilidade, Dissertação de M.Sc., UFPE, Recife, PE, Brasil, 2003.

[14] FERREIRA, S.R.M. FUCALE S.P., "Evaluation of the collapsibility of coils in the semiarid region of Pernambuco", Brazil, Journal of Civil Engineering and Architecture, v. 8, n. 10, pp. 1285-1292. 2014.

[15] TORRES, M. S., Avaliação da colapsibilidade e da resistência de ponta de um solo de Petrolina devido à inundação, Dissertação de M.Sc., UFPE, Recife, PE, Brasil, 2014.

[16] ASSOCIAÇÃO BRASILEIRA DE NORMAS TÉCNICAS. NBR 6457 - Amostras de solo - preparação para ensaios de compactação e ensaios de caracterização - Método de ensaio. Rio de Janeiro, RJ, Brasil, 1986.

[17] _ . NBR 7181 - Solo - análise granulométrica - procedimento - Método de ensaio. Rio de Janeiro, RJ, Brasil, 1984.

[18] _ _ . NBR 6508 - Solo - grãos de solo que passam na peneira de 4,8 mm: determinação da massa especifica - Método de ensaio. Rio de Janeiro, RJ, Brasil, 1984.

[19] _ _ . NBR 6459 - Solo - determinação do limite de liquidez - procedimento - Método de ensaio. Rio de Janeiro, RJ, Brasil, 1984.

[20] _ _ NBR 7180 - Solo - determinação do limite de plasticidade - procedimento - Método de ensaio. Rio de Janeiro, RJ, Brasil, 1984.

[21] _. NBR 7182 - Solo - ensaio de compactação - procedimento - Método de ensaio. Rio de Janeiro, RJ, Brasil, 1986.

[22] EMBRAPA - Empresa Brasileira de Pesquisa Agropecuária, Manual de Métodos de Análise de Solo. 2.ed. Rio de Janeiro, Centro Nacional de Pesquisa de Solos, 1997.

[23] MCGOWN, A., COLLINS, K., "The microfabrics of some expansive and collapsing soils", In: Proceedins of the $5^{\text {th }}$ Pan-american Conference, Soil Mechanics and Foundation Engineering, v.1, pp. 332332, Buenos Aires. 1975.

[24] JENNINGS, J.E. AND KNIGHT, K. "A guide to construction on or with materials exhibiting additional settlement due to collapse of grain structure". In: Proceedings of the $6^{\text {th }}$ African Conference on Soil Mechanics and Foundation Engineering, pp. 99 -105, Durban, 1975.

[25] ASSOCIAÇÃO BRASILEIRA DE NORMAS TÉCNICAS. NBR 8036 - Programação de sondagens de simples reconhecimento dos solos para fundações de edifícios, Rio de Janeiro, RJ, Brasil, 1983.

[26] _ _ NBR 6484 - Solo - Sondagens de simples reconhecimento com SPT - Método de ensaio. Rio de Janeiro, RJ, Brasil, 2001. . NBR 6502 - Rochas e solos - Terminologia. Rio de Janeiro, RJ, Brasil, 1995.

[28] STOLF, R. "Teoria e teste experimental de fórmulas de transformação dos dados de penetrômetro de impacto em resistência do solo", Revista Brasileira de Ciência do Solo, Campinas, v. 15, pp. 229-235, 1991.

[29] FERREIRA, S. R., LACERDA, W. A., "Fatores que influenciam a variação de volume devido à inundação de solos colapsíveis", Revista Solos e Rochas, v. 16, n. 4, pp. 254-253, 1993.

[30] ROAD AND TRANSPORT RESEARCH ASSOCIATION, Working Group for Foundation and Soils Engineering. In: Dynamic Plate-Load Testing with the Aid of the Light Drop-Weight TesterTechnical, Test Code for Soil and Rock Mechanics in Road Constructions TP BF-StB Part B 8.3, German, 2003.

[31] USBR., Earth Manual, Pat1. 3 ed., Bereau of Reclamation, Denver, 1988.

[32] VILAR, O.M., RODRIGUES, R.A., "Revisiting classical methods to identify collapsible soils", Soils and Rocks, v.38, n.3 pp. 265-278. 2015. 
[33] ALONSO, E. E., GENS, A. E., HIGHT, D. W. "Special Problems Soils", In: Proceedings of the $9^{\text {th }}$ European Conference on Soil Mechanics and Foundation Engineering, General Report, pp. 5.1-5.60, Dublin, 1987.

[34] BREWER, R., Fabric and Mineral Analysis of Soils. Huntigton, New York, 1976.

[35] VILAR, O.M., FERREIRA, S.R.M., "Solos colapsíveis e expansivos", In: Solos não saturados no contexto geotécnico,1 ed., capítulo 15, São Paulo, ABMS, 2015.

[36] REZNIK, Y. M. "Discurssion of detemination of collapse potential of soils", Geot. Test J., ASCE, v. 12, n. 3, pp. 248-249, 1989.

[37] TERRATEST GMBH. Instruction Manual Light Weight Deflectometer for the dynamic plate load test., Berlin, 2013. 